\title{
ПРЕДПРИНИМАТЕЛЬСТВО В СОВРЕМЕННОЙ ЭКОНОМИКЕ
}

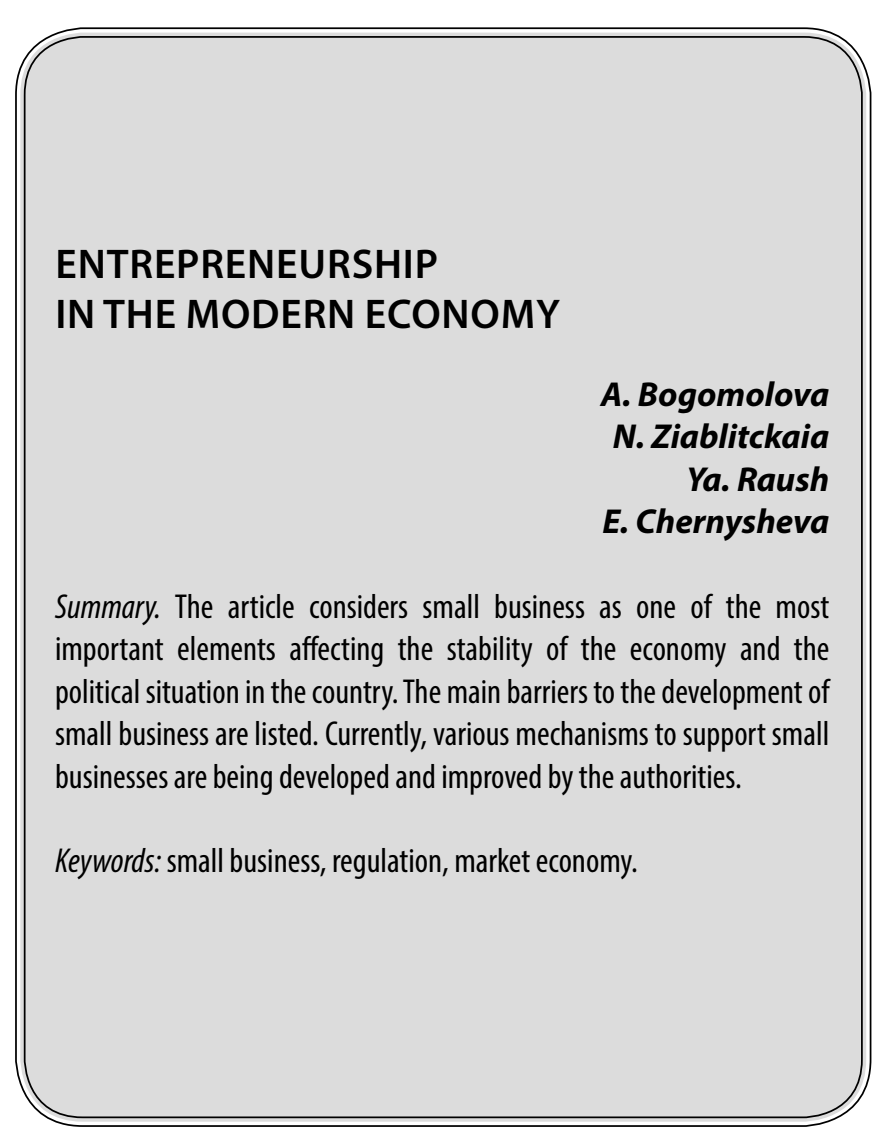

$\Gamma$

лавными критериями эффективности государства Президент страны в своём послании Федеральному Собранию определил два показателя - доходы и качество жизни. Важную роль в их повышении играет развитие предпринимательства.

Рыночная экономика предполагает повышение частной предпринимательской инициативы. Ведь бизнес серьезно влияет на экономику с помощью нескольких ключевых факторов: это, прежде всего, занятость, налоги, производство продукции и услуг. Именно они и определяют рост ВВП, а потому поддержка этой сферы действительно важна.

Доля участия государства в экономике все еще остается высокой. Частный сектор должен выступить ключевым драйвером роста экономики и производительности труда. А планы развития каждой области должны учитывать сильные позиции и укреплять их как якорные. Нельзя распылять средства и силы на проекты и сферы, от которых не будет большого толка.
Богомолова Алёна Андреевна

Филиал ФГАОУ ВО «Южно-Уральский государственный университет (НИУ)»,

2. Нижневартовск

bogomolova_aa@list.ru

Зяблицкая Наталья Викторовна

Д.э.н., филиал ФГАОУ ВО «Южно-Уральский государственный университет (НИУ)»,

2. Нижневартовск

Рауш Яна Сергеевна

Филиал ФГАОУ ВО «Южно-Уральский государственный университет (НИУ)»,

2. Нижневартовск

Чернышева Елена Михайловна

Филиал ФГАОУ ВО «Южно-Уральский государственный университет (НИУ)»,

г. Нижневартовск

Аннотация. В статье рассматривается малый бизнес как один из важнейших элементов, влияющих на устойчивость экономики и политической ситуации в стране. Перечислены основные барьеры на пути развития малого предпринимательства. В настоящее время со стороны органов власти разрабатываются и совершенствуются различные механизмы поддержки малого бизнеса.

Ключевые слова: малый бизнес, регулирование, рыночная экономика.

Новая модель экономического роста, основана на снижении роли государства и развитии бизнеса. ВВП, должен расти за счет повышения эффективности, производительности труда, усиления малого и среднего бизнеса.

Принимая во внимание все более актуализирующийся вопрос высвобождения рабочих мест в связи с автоматизацией многих рабочих процессов, массовое предпринимательство окажет положительный эффект как на экономику страны, так и на жизнь населения страны.

В последние годы доля МСБ в экономике России остается на уровне 25-27\%. Задача - довести ее до $35 \%$ к 2025 году и не менее 50\% - к 2050-му. В нынешнем году планируется достигнуть показателя в 28,2\%.

Все условия для этого есть. Бизнес-климат в России улучшается, устраняются барьеры для предпринимателей. 


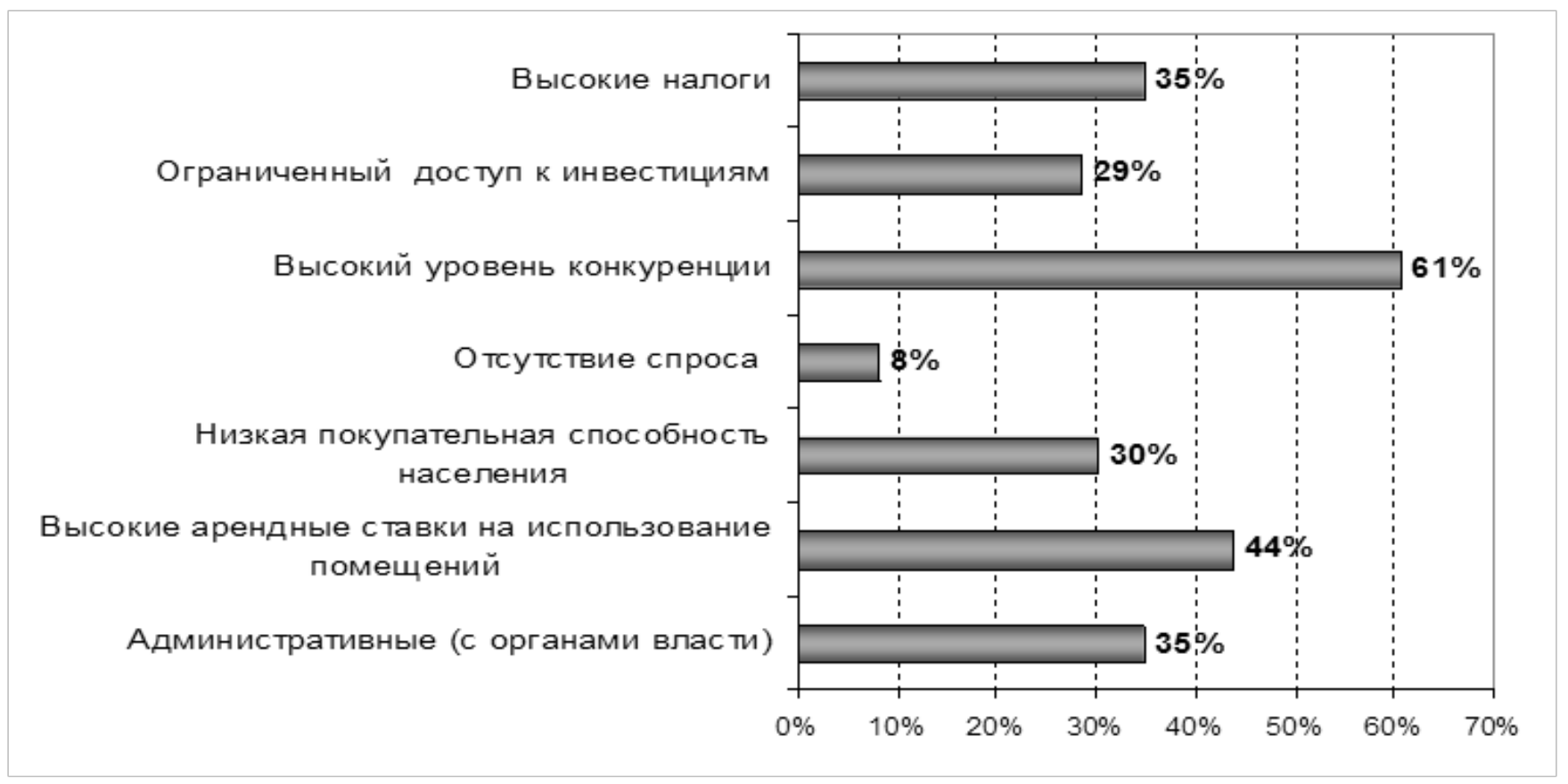

Рис. 1. С какими проблемами внешнего характера Вам приходится сталкиваться в процессе деятельности? [3]

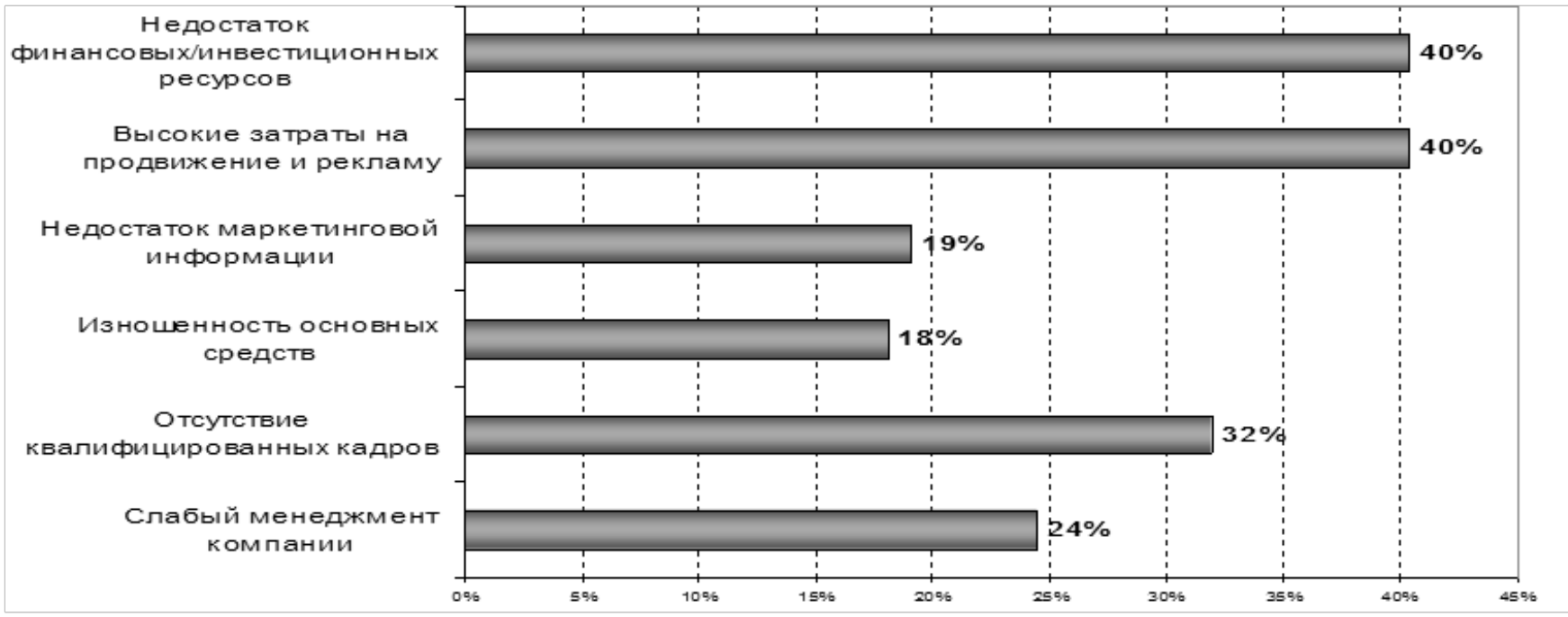

Рис. 2. С какими внутренними проблемами Вам приходится сталкиваться в процессе деятельности? [3]

Всесторонняя поддержка бизнеса уже приносит ощутимые плоды. Так, рост экономики в прошлом году $(4,1 \%)$ сопровождался опережающим повышением реальных доходов населения на 4,4\%.

Однако, в свете нового финансирования необходимо поднимать вопрос повышения ответственности бизнеса перед государством.
Государственные средства необходимо выделять только тем предпринимателям, которые готовы модернизироваться и вкладываться в новую технику. Всесторонняя поддержка бизнесу по сравнению с 2018 годом число субъектов малого предпринимательства увеличилось на 8,3\%, появилось около 30 тыс. новых субъектов малого бизнеса. Так что говорить о том, что положение предпринимателей ухудшилось, нельзя. 


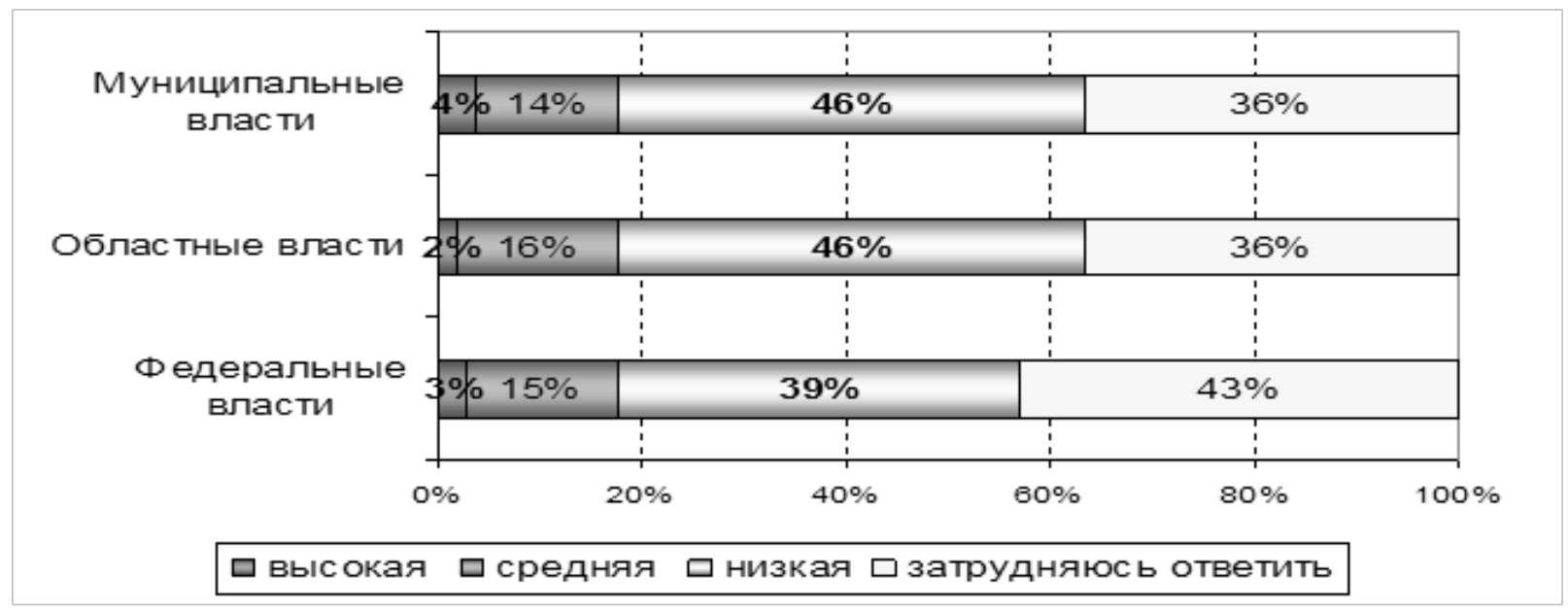

Рис. 3. Оцените эффективность работы федеральных, областных и местных (муниципальных) властей [3]

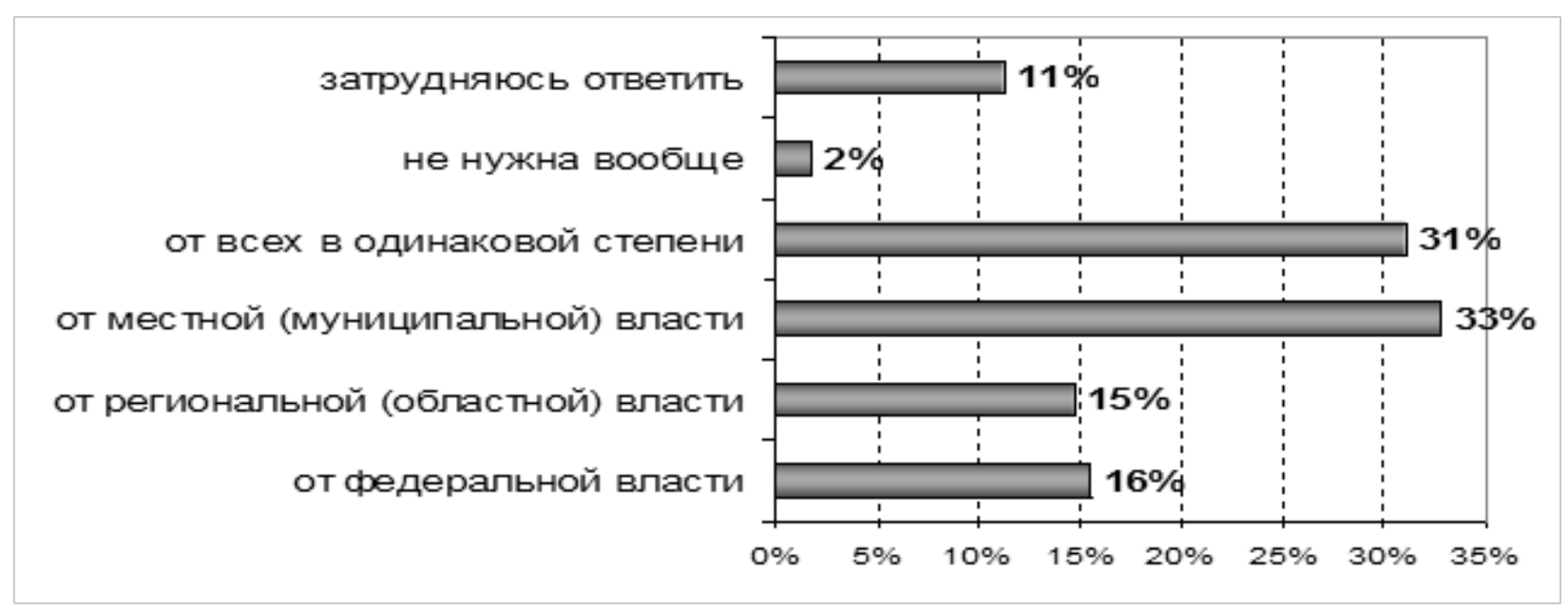

Рис. 4. От какого уровня власти (федерального, регионального, местного), по Вашему мнению, должна быть наибольшая поддержка? [3]

В целях получения наиболее полноценной картины по развитию бизнеса, а также в поисках ответов на волнующие вопросы о проблемах взаимодействия бизнеса и государственной власти, и мерах по их решению, был проведен мониторинг, результаты которого представлены в статье.

Прежде, чем определить спектр необходимой поддержки бизнесу, имело смысл узнать, с какими же проблемами на текущий момент сталкиваются предприятия в своей деятельности.

Предлагаемый респондентам перечень определялся по двум критериям: проблемы внешнего характера и внутренние проблемы бизнеса.
Согласно полученным данным, к проблемам внешнего характера предприниматели отнесли:

- высокий уровень конкуренции - 61\%;

- высокие арендные ставки на помещения - 44\%;

- высокие налоги - 35\%;

- административные проблемы - 35\%.

Среди проблем внутреннего характера предприниматели выделили:

- недостаток финансовых, инвестиционных ресурсов - 40\%;

- высокие затраты на продвижение и рекламу 40\%;

- отсутствие квалифицированных кадров $32 \%$. 


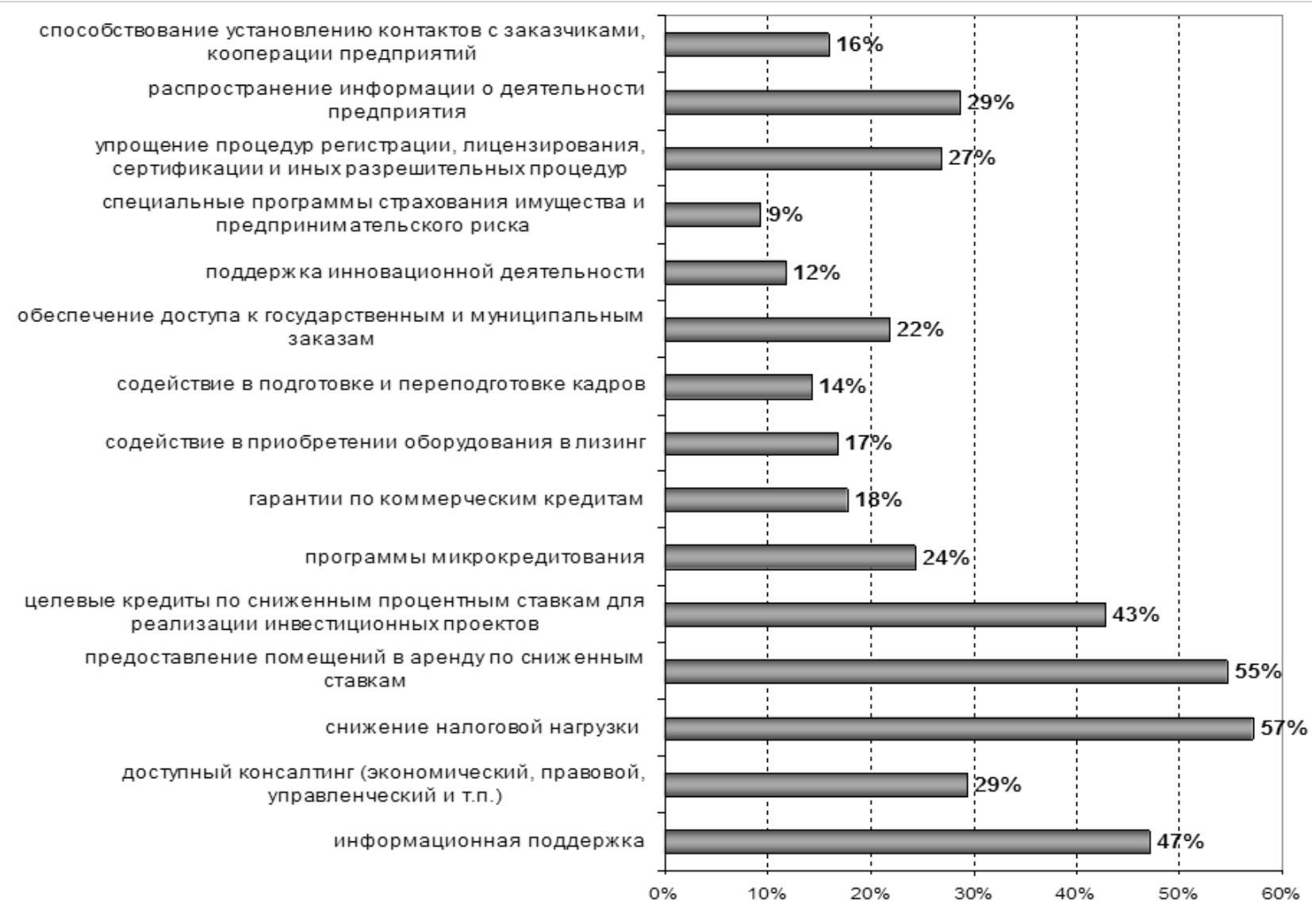

Рис. 5. В чем может быть эффективность поддержки государства для бизнеса [3]

Текущие данные совпадают с данными предыдущего мониторинга (2018 г.). Проблемы у бизнеса остались прежними.

Так, в 2019 году среди основных проблем предприятия выделяли: нехватку финансовых средств - 56\%, высокие арендные ставки - 52\%, а также высокие налоги.

Прежде чем остановиться на конечном пункте данного мониторинга, следует рассмотреть, как же оценивают предприниматели на данный момент работу федеральных, региональных и муниципальных властей и от кого из них они в первую очередь ожидают помощи и поддержки.

Итак, как мы видим, в отношении эффективности у всех властей практически одинаковые показатели. Причем большинство респондентов оценивает работу властей по поддержке бизнеса как достаточно низкую.

При этом большинство отмечает, что, прежде всего, поддержки и помощи они ожидают все-таки от государственной и муниципальной власти.
Имея представление о насущных проблемах компаний, целесообразно уточнить, какой именно поддержки предприниматели ожидают от Программы.

Итак, прежде всего, бизнес нуждается в снижении налоговой нагрузки (57\%). Существенным финансовым подспорьем при этом для респондентов было бы снижение процентных ставок на целевые кредиты (43\%) и развитие микрокредитования.

Актуальным остается вопрос о предоставлении помещений по сниженным арендным ставкам (55\%). Стоимость арендной платы постоянно увеличивается. Для бизнеса финансовая нагрузка в связи с увеличением арендной платы становится «неподъемной». Рост арендной платы стимулируется дефицитом ввода новых объектов коммерческой недвижимости и активной продажей государственных и муниципальных зданий с переводом всех бывших арендаторов на рыночный уровень аренды.

Можно с уверенностью прогнозировать, что такая ситуация с ростом аренды будет продолжаться в бли- 
жайшие 3-5 лет. Дополнительно ситуацию усугубляет и тот факт, что нет достоверной и полной информации о предоставляемых в аренду производственных помещениях. Не обладая достаточно полной информацией, предприниматель не может ориентироваться в новых рыночных условиях. Учитывая, что данная проблема не является временной, а имеет системный долгосрочный характер, требуются более активные и эффективные меры со стороны муниципалитета для снижения этого отрицательного воздействия на предпринимательскую среду, преимущественно для сектора начинающих предпринимателей и производственно-инновационного бизнеса.

Проведенный многосторонний анализ свидетельствует, что в настоящее время в России, во многом благодаря предпринятым мероприятиям по государственной поддержке предпринимательства, ситуация достаточно стабильна. Каждое третье предприятие с уверенностью смотрит в будущее, планируя дальнейшее развитие.
Таким образом, нынешнее взаимодействие бизнеса и власти можно назвать весьма неоднозначным. С одной стороны, Россия очень привлекательна в инвестиционном плане, как со стороны зарубежных предпринимателей, так и отечественных. С другой стороны, некоторые условия, которые ставит власть бизнесменам, являются неприемлемыми, «пугающими» и просто тормозящими поток инвестиций в страну.

Например, власть и бизнес не могут найти точек соприкосновения относительно таможни и логистики. Крупные инвесторы для того, чтобы зайти в Россию, требуют наличие развитых транспортных путей, инфраструктуры и ресурсов.

Возможности для всех представителей предпринимательской среды должны быть равными для всех. Только тогда власть и бизнес России сумеют построить эффективные взаимоотношения, которые неизменно приведут к процветанию страны и стабилизации экономики.

\section{ЛИТЕРАТУРА}

1. Кузьмина Е. Е. Организация предпринимательской деятельности [Электронный ресурс]: учебное пособие для бакалавров /Е.Е. Кузьмина, Л. П. Кузьмина. - 2-е изд., перераб. и доп.— Москва: Юрайт, 2016. — Режим доступа: http://www.biblio-online.ru.

2. Рвачев А. Л. Государственное регулирование предпринимательской деятельности. М.: Экономика, 2019. - 213 c.

3. Першин А.А., Веснин А. В. Общественное мнение: сущность и его роль в управлении государством // Право и образование.—2019. — № 5.—C. 105-110.

(с) Богомолова Алёна Андреевна ( bogomolova_aa@list.ru ), Зяблицкая Наталья Викторовна,

Рауш Яна Сергеевна, Чернышева Елена Михайловна.

Журнал «Современная наука: актуальные проблемы теории и практики» 